\title{
Methods for biological monitoring: Biological interactions in communities of subtidal sediments
}

\author{
J. A. Berge \\ Institute for Marine Biology and Limnology, Department of Marine Zoology and Marine \\ Chemistry, University of Oslo; Oslo, Norway
}

\begin{abstract}
Predation has been demonstrated to be of fundamental importance in structuring benthic communities in the intertidal zone. The aim of the present investigation was to elucidate some of the effects of predation on structuring communities in unvegetated subtidal sediments. Field manipulative cage experiments were performed on sediment in the inner part of the Oslofjord (Norway), where the species composition was typical for a moderately organically enriched sediment. Sediment from this area was transferred to an area not suspected a priori to be seriously affected by organic pollution, and the effect of predation on the fauna was evaluated. Predation effects were not observed in the Oslofjord experiments partially because of extensive obstruction of recruitment to the sediment by settlement of Polydora antennata on the cage $e_{i}$ however, further experiments are in progress in this area. No such settling was observed in the unpolluted area. Here 63 taxonomic groups were identified, 57 in the control and 50 in the cages; 43 taxonomic groups were found in both the cage and the control. The total number of individuals was significantly higher in the cage (4779) than in the control (2849). The fauna recruited to the sediment in the cage responded to decreased predation by macropredators by a significant reduction in diversity. Of the 10 most abundant groups 3 (Tellinacea, Syllidae and Pholoë minuta) were significantly more abundant in the cage than in the control; 3 others (Prionospio malmgreni, Microphthalmus abberans and Paraonidea) were significantly more abundant in the control. It is concluded that in an unpolluted area predation is an important factor in controlling numbers of at least some of the most abundant species. However, the effect of predation does not seem to be of the same importance in the subtidal as has previously been recognized for unvegetated intertidal mudflats.
\end{abstract}

\section{INTRODUCTION}

Monitoring of marine communities in order to detect pollution effects is based on the idea that undetectable small scale physiological or behavioural effects at the individual level are more readily detected at the community level. However, present ecological theory and eco-physiological knowledge cannot predict the response at the community level following small scale fluctuations in natural variables. Therefore, there is at present a high level of background noise in the measurement of pollution effects on marine communities.

One of the natural variables affecting community structure is predation. In the rocky intertidal zone attachment space is often a limited resource (Connell, 1961a, b, 1972). The usual outcome of competition for this resource is that competitive superior species will exclude inferior species and the substrate is therefore monopolized by one or a few species. Menge \& Sutherland (1976) and Peterson (1979a) demonstrated that mytilids in 
areas with few predators will outcompete balanids and monopolize the substrate. However, several processes (for example, predation) may interrupt the competitive interactions so that monopolization is not achieved. Peterson (1979a) investigated the relative importance of predation and competition in organizing an intertidal epifaunal community. He showed that in a protected area predators prevent monopolization of the mid and low intertidal by the competitive dominant Mytilus.

In intertidal mudflats Reise $(1977 a, b, 1978)$ found that reduced predation under cages resulted in higher abundance and altered composition of the fauna. Generally, the exclusion of predators from unvegetated intertidal flats results in a dramatic increase in macrobenthos abundance. However, in an extensive investigation Commito (1976) found no support for the hypothesis that fish and crabs control the structure of two softbottom intertidal communities in the Newport River estuary, North Carolina, USA. In eelgrass and Corophium beds Reise (1978) found that exclusion cages did not have the same dramatic effect on abundance as found on unvegetated sand and mudflats; some species responded with a higher abundance within the cage and others with a higher abundance in the control. Young \& Young (1978), observing exclusion cages in seagrass associations, found that total macrofauna species were more abundant in cages than in controls, but only certain species had their highest densities inside the cages. A possible explanation for the reduced effect of predation on abundance of macrobenthos in seagrass associations as compared with unvegetated sand and mudflats is that the grasses provide physical refuges from predation (Reise, 1978).

Generally, predation seems to be an important variable in determining community structure both in intertidal flats and in protected areas on the middle and low intertidal rocky shore. In the rocky intertidal reduced predation often results in monopolization of the substrate by one or two species, and in unvegetated intertidal flats reduced predation leads to an increase in abundance and diversity (Peterson, 1979b).

Few experiments have been designed to evaluate the effect of predation on community structure in subtidal sediments. Blegvad (1927) performed experiments at $5.5 \mathrm{~m}$ depth at Nissum Bredning in Denmark, and Virnstein $(1977,1979)$ investigated the effect of predation on the infauna at a depth of $1.4 \mathrm{~m}$ on a sandy bottom at Chesapeake bay, USA. Arntz (1977) performed manipulative cage experiments at a depth of $20 \mathrm{~m}$ in the Kiel Bight in order to study transfer of benthic biomass to demersal fish. Blegvad and Virnstein found a considerable increase in abundance when predation pressure was reduced by the exclusion cages, thus resembling the results from intertidal sand and mudflats as found by Reise (1978). The results from Arntz's experiments are more difficult to interpret because of development of unusually high numbers of predators inside the cages.

The aim of the present investigation was to try to elucidate some of the effects of predation in structuring soft bottom communities in subtidal areas where physical and chemical variables are more stable than in the intertidal and in the shallow subtidal. The subtidal area below the pycnocline should be a priori more convenient for biological monitoring because of its more stable environmental variables, though one must bear in mind that many subtidal organisms are stenotopic while intertidal organisms often are eurytopic. 


\section{METHODS}

The effect of predation was evaluated by performing field manipulative cage experiments. The basic idea in such experiments is that a part of the substrate is protected from predation by constructing a cage. Predation effects are determined by comparing faunal composition and abundance inside and outside the cage. Higher abundance inside the cage indicates that predation is involved in controlling abundance outside the cage. Altered species composition may indicate the effect of predation on competitive interactions.

Sediment for the experiments was collected at the experimental site in the Oslofjord $\left(10^{\circ} 37^{\prime} 64^{\prime \prime} \mathrm{E}, 59^{\circ} 52^{\prime} 26^{\prime \prime} \mathrm{N}\right.$, see Fig. 1) using a triangular dredge. In the laboratory the sediment was homogenized in a cement mixer; stones, mollusc shells and other larger objects were removed. The homogenized sediment was filled into grey PVC experimental boxes $(60 \times 40 \times 12.5 \mathrm{~cm}$, see Fig. 2). Homogenization minimised the possibility of sediment heterogeneity. The boxes with the sediment were frozen in order to kill all

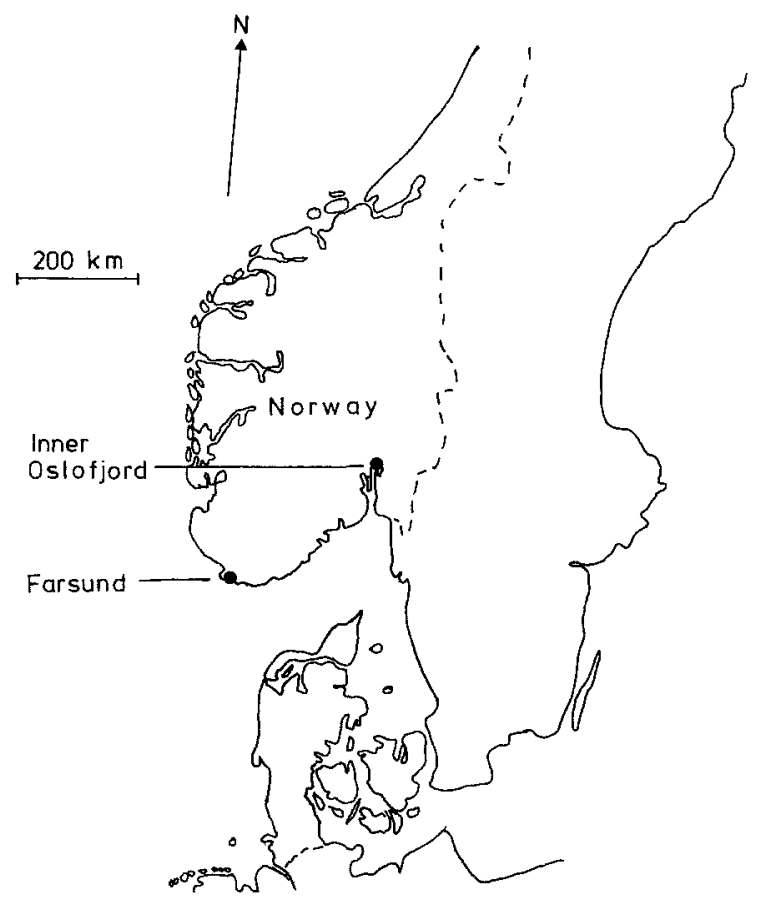

Fig. 1. Chart showing experimental sites. Oslofjord $\left(10^{\circ} 37^{\prime} 64^{\prime \prime} \mathrm{E}, 59^{\circ} 52^{\prime} 26^{\prime \prime} \mathrm{N}\right)$. Farsund $\left(6^{\circ} 49^{\prime} 15^{\prime \prime}\right.$ E, $58^{\circ} 4^{\prime} 6^{\prime \prime} N$ )

macrofauna and to prevent washing out the sediment when submerging the boxes in the sea. One half of each experimental box (referred to as "cage") was covered by a 3-mm mesh net for exclusion of epibenthic macropredators from the sediment inside the cage. The other half of each box is referred to as "control". The experimental boxes were submerged (a) in the inner Oslofjord at $23 \mathrm{~m}$ depth and (b) on the south coast of Norway 
near Farsund $\left(6^{\circ} 49^{\prime} 15^{\prime \prime} \mathrm{E}, 58^{\circ} 4^{\prime} 6^{\prime \prime} \mathrm{N}\right.$, see Fig. 1) at a depth of $18 \mathrm{~m}$. The sea bed at both stations is almost horizontal. No or very few macroalgae were present, and so far no structures above the surface of the sediment which may obstruct predators have been observed.

The sediment at the station in the inner Oslofjord had a high content of faecal pellets and the fauna in the area was typical for a moderately organic enriched sediment. Common taxa were Polydora, Chaetozone, Cirratulus, Ophiodromus, Lagis, Capitellidae, Dorvillidae and Thyasira. The sediment at Farsund was a priori not suspected to be organically enriched. It was mainly composed of mollusc shell fragments and some mud and sand. The natural faunal composition of the sediment was not known in any detail.

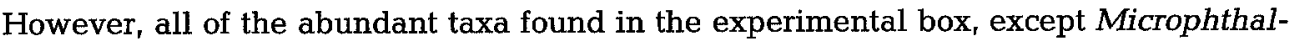
mus abberans, were found in comparable abundance on the natural sediment outside the box. Temperature and salinity were recorded only at the station in the inner Oslofjord. During the experimental period it varied between the limits of $7-8.5^{\circ} \mathrm{C}$ and $31.5-32.5 \% \mathrm{~S}$ at a depth of $23 \mathrm{~m}$. The experimental boxes were submerged in the inner

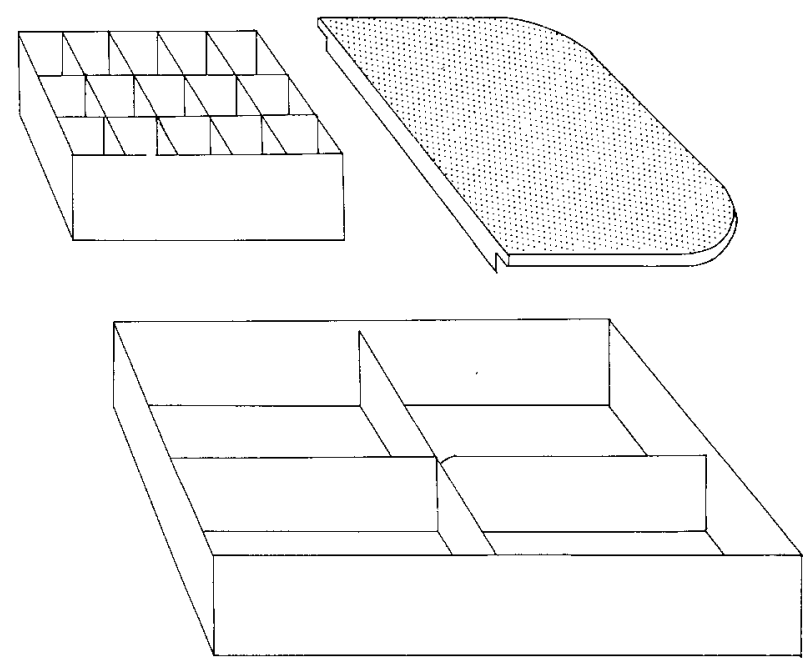

Fig. 2. Experimental box with net cover and grid divider

Oslofjord on 27 Jan. 1978 and at Farsund on 25. Feb. 1978. The boxes were recovered by scuba divers after 7 months of submergence. Several other experimental boxes have been submerged in the inner Oslofjord, but the results from these experiments are only briefly mentioned in this paper.Prior to recovery, the predator-exclusion netwas removed and 4 grids (see Fig. 2) were pushed into the experimental box, dividing this into 60 compartments (surface area $27.5 \mathrm{~cm}^{2}$ ). A lid was fastened to the box to avoid flushing of the sediment when taken to the surface. In the laboratory $150 \mathrm{ml}$ of sediment, corresponding to $5.5 \mathrm{~cm}$ depth, was removed from each compartment. Marginal compartments were excluded in order to avoid possible edge effects. The sediment was preserved in $10 \%$ neutralized formaldehyde and washed through $500-\mu \mathrm{m}$ and $250-\mu \mathrm{m}$ sieves. The remains on the sieves were stained with rose bengal. The animals were sorted under a 
binocular microscope and all animals, except nematodes and protozoans were identified to species or taxon.

In order to measure to what extent the predator-exclusion net reduces sedimentation under the cage, one experimental box with 24 jars (12 in control and 12 in cage) were submerged for 3 months from 11 May 1978 in the inner Oslofjord. The jars were closed during submergence and recovery. The dry weight (dried at $60^{\circ} \mathrm{C}$ until constant weight) of the content in each jar was determined, and cage and control were compared.

The light reduction caused by the predator-exclusion net was determined with a light sensor (United Detector Technology, model $80 \mathrm{X}$ photometer). On land, 10 alternating light intensity measurements were made in cage and control in one experimental box. Measurements were made at the level of the sediment surface.

For statistics Shannon Wiener diversity index $(H)$, Pielous evenness index $(J)$, total number of specimens and taxa in each compartment were calculated. For each of the 2 experiments performed, the fauna was divided into a certain number of taxonomic groups so that each group was represented in both cage and control. The mean number of individuals within a group was higher than 1 . The groups were ranked according to abundance in control. Abundance of animals within cage and control was then plotted as a function of rank in control. The effect of predation can then be visualized by comparing the curve for cage and control.

\section{RESULTS}

\section{Sedimentation and light measurements}

The mean weight of the content in each jar under cage was $3.77 \mathrm{~g}(\mathrm{~S} . \mathrm{D} .=0.96)$ and in control $4.35 \mathrm{~g}$ (S. D. $=1.13$ ); a $t$-test however could not indicate any difference in contents between cage and control at the 0.05 level of significance. Settlement of Polydora on the net covering the cage was observed.

Measurements showed a light intensity reduction of $25.5 \%$ under the cage as compared to the control when measured on land with no animals or sediment on the net.

\section{Experiments in the inner Oslofjord}

On recovery of the experimental box an extensive amount of Polydora spp. (mainly Polydora antennata) was observed on the net covering the cage. A total of 23 taxa was identified in the experimental box, 20 in the control and 18 in the cage. The 5 most abundant taxa were Polydora, Capitellidae, Chaetozone, Dorvellidae and Pholoë. The mean number of individuals in each compartment in the control (507) was significantly higher than in the cage (103). The mean number of individuals of Polydora in the control was 381 and in the cage 52; this difference is caused, at least partially, by the extensive amount of Polydora on the net covering the cage. Therefore Polydora was excluded in calculations of diversity and evenness, giving $H=2.61, J=0.61$ in the control and $H=2.88, J=0.70$ in the cage. However, neither mean diversity nor mean evenness was significantly higher in the cage than in the control ( $t$-test, $P=0.05$ ). The fauna in the experimental box was divided into 8 groups (see Table 1). All groups were represented with a higher number of individuals in the control than in the cage (see Fig. 3). Of the 
Table 1. Groups in control ranked according to decreasing abundance (Inner Oslofjord, Vássholmen; 7-month experiments)

\begin{tabular}{|cl|}
\hline Rank in control & \multicolumn{1}{c|}{ Species/taxa } \\
\hline 1 & Polydora spp. \\
2 & Capitellidae (Capitomastus and Capitella) \\
3 & Chaetozone setosa Malmgren \\
4 & Other taxa (12 in control and 10 in cage) \\
5 & Dorvellidae (Ophryotrocha and Schistomeringos) \\
6 & Pholoe minuta (Fabricius) \\
7 & Polychaeta, indet. \\
8 & Harpacticoidea \\
\hline
\end{tabular}

total number of animals $74.3 \%$ were retained on $500-\mu \mathrm{m}$ sieves in the control and $36.6 \%$ in the cage. The corresponding results after excluding Polydora were $54 \%$ and $36 \%$, respectively. Ranking the $\mathbf{8}$ groups found in cage and control according to abundance and testing for the existence of a correlation between rank number in the cage and in the control reveals a correlation coefficient $R_{s}=0.94(N=7)$ (Spearmans rank correlation coefficient). This gives a highly significant correlation $(P=0.001)$ (see Fig. $5 \mathrm{~b}$ ). Two other experiments have been performed in the inner Oslofjord: one in the period 2 Aug.-9 Nov. 1977 and another in the period 27 Jan.-21 Apr. 1978. In none of these experiments was the total abundance in the cage higher than in the control. In both experiments the abundance of Polydora was higher in the control than in the cage,

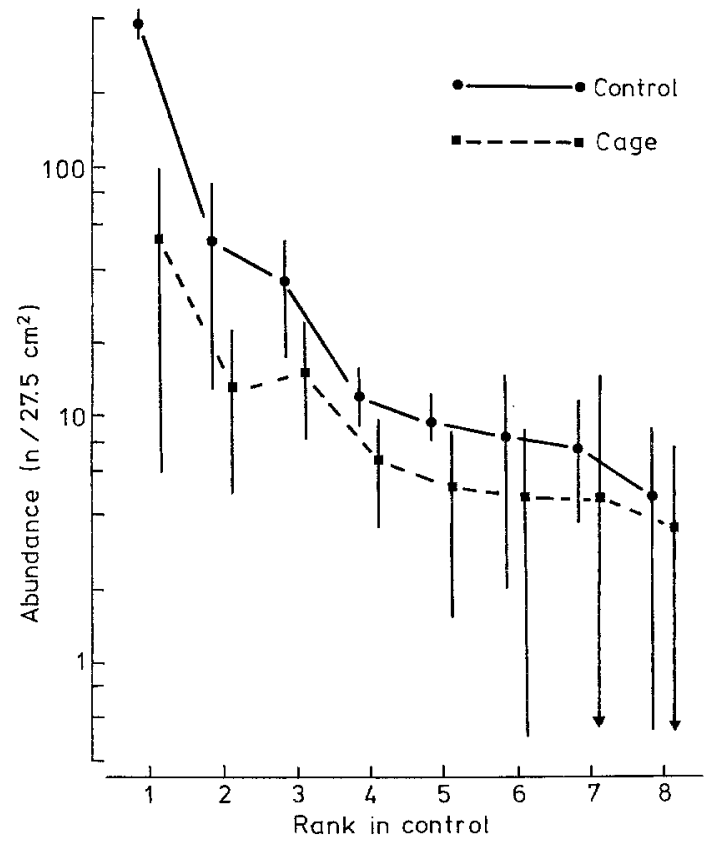

Fig. 3. Results from 7-month experiments in inner Oslofjord. Abundance of animals in cage and control as a function of rank number in control. Vertical lines indicate $\pm 1 \mathrm{~S}$. D. 
although, only some sediment and no visible fouling was found on the net covering the cage.

\section{Experiments at Farsund}

No sediment or animals were visible on the net covering the cage on recovery. A total of 63 taxonomic groups were identified, 57 in the control and 50 in the cage; 43 were found both in the cage and the control. The mean number of individuals in each compartment under the cage (398) was significantly higher ( $t$-test, $P=0.05$ ) than in the control (237). Diversity and evenness in the control $(2.69,0.46$ respectively) were higher than in the cage $(2.32,0.41)$. Mean diversity for each compartment in the control $(2.43)$ was significantly higher than in the cage (2.23). Mean evenness was also higher in the control, though this difference was not significant ( $t$-test, $P=0.05$ ). The animals in the experimental box were divided into 11 groups (see Table 2); of these 3 (Tellinacea, Syllidae and Pholoe minuta) were significantly more abundant in the cage and 3 (Prionospio malmgreni, Microphthalmus abberans and Paraonidea) were significantly more abundant in the control. In the 5 remaining groups no significant difference between the cage and the control was found (results are summarized in Fig. 4). Out of 2849 individuals in the control $20 \%$ were retained on sieves with mesh size of $500 \mu \mathrm{m}$ whereas the corresponding results fron the cage (4779) were $21 \%$. In these experiments there was a highly significant $(P=0.01)$ correlation between rank in cage and rank in control, but the correlation coefficient is lower $\left(R_{s}=0.77, N=10\right)$ than in the experiment in the inner Oslofjord (see Fig. 5c).

Table 2. Groups in control ranked according to decreasing abundance

(Farsund; 7-month experiments)

\begin{tabular}{|cl|}
\hline Rank in control & \multicolumn{1}{c|}{ Species/taxa } \\
\hline 1 & Harpacticoidea \\
2 & Tellinacea \\
3 & Others (47 in control and 41 in cage) \\
4 & Ophiuroidea, spat <500 $\mu \mathrm{m}$ \\
5 & Prionospio malmgreni (Claparède) \\
6 & Exogene naidina Oersted and Sphaerosyllis tetralix Eliason \\
7 & Sphaerosyllis hysterix Claparède \\
8 & Paraonidea (Paraonis fulgens?) \\
9 & Halacaridae \\
10 & Microphthalmus abberans (Webster \& Benedict) \\
11 & Pholoë minuta (Fabricius) \\
\hline
\end{tabular}

\section{DISCUSSION}

\section{Limitations of the method}

The basic idea of the experiments was that reduced predation pressure, if existing, would result in an increased prey organism abundance in the cage. However, several difficulties arise in the interpretation of the results for cage experiments, since factors other than predation may influence the results. 


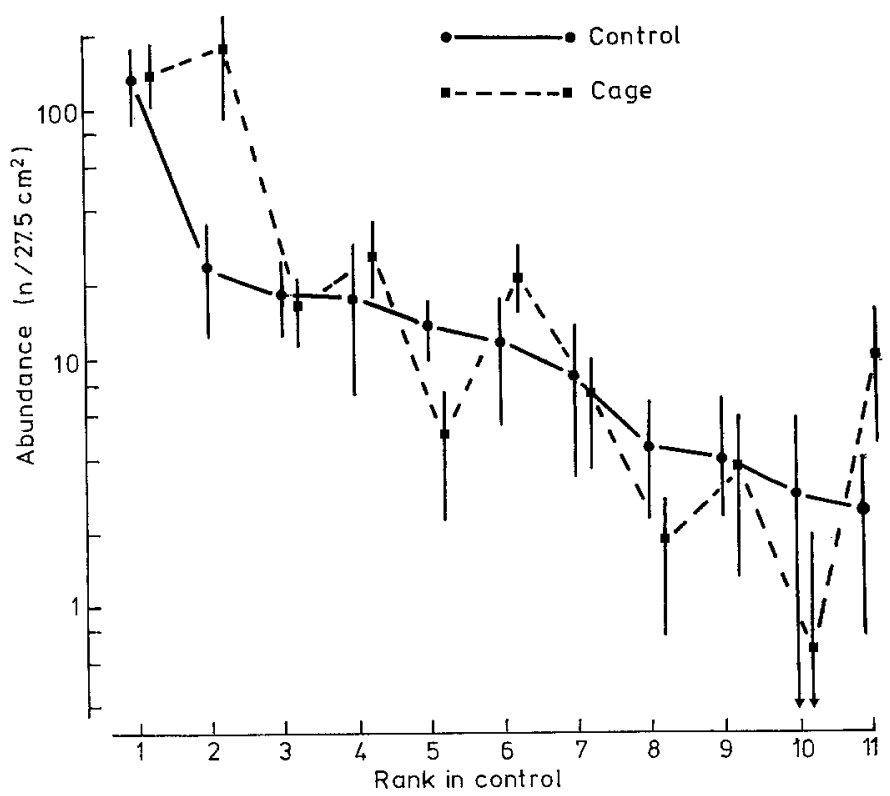

Fig. 4. Results from 7-month experiments at Farsund. Abundance of animals in cage and control as a function of rank number in control. Vertical lines indicate $\pm 1 \mathrm{~S}$. D.

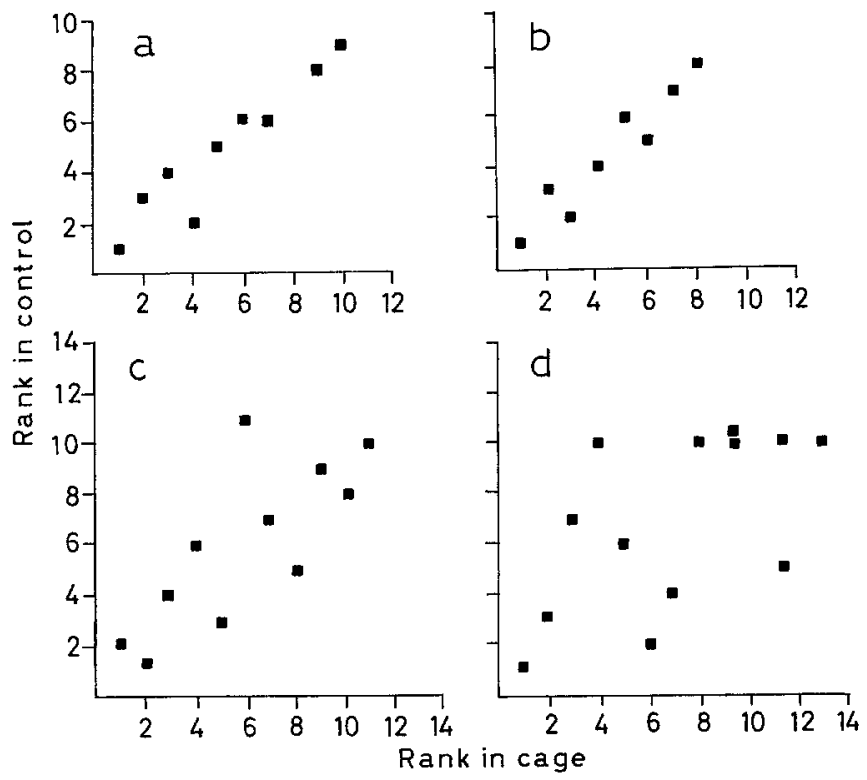

Fig. 5. Rank in control as a function of rank in cage. (a) Inner Oslofjord, 3-month experiments. (b) Inner Oslofjord, 7-month experiments. (c) Farsund, 7-month experiments. (d) Species common to both cage and control. Data from experiments on unvegetated mudflat (Reise, 1978, Table 7); 11 species were exclusively found in the cage whereas none were exclusively found in the control 
Enhanced abundance of some species may result in reduced competitive success for taxa not directly affected by predation. This could result in reduced abundance for competitively inferior species in the cage.

The cage modifies some physical variables. In this investigation light intensity is reduced by at least $25 \%$ in the cage. Because animals are known to respond to variations in the physical variables of their habitat, a difference in community structure in the cage, compared with the control, might not be due to predation, but rather to modifications of the physical environment. For example, a photonegative larva might aggregate under the cage when settling. Enhanced sedimentation in the cage might also be a problem. In my experiments no significant increase of sediment in the cage was observed. However, an extensive settlement of Polydora on the net covering the cage may have reduced sedimentation under the net. From cage experiments on rocky substrate enhanced sedimentation is known to be of importance ( $\mathrm{H}$. Christie, personal communication).

The net itself and the presence of fouling organisms might obstruct larval settlement. Results from cage experiments in the inner Oslofjord are clearly affected by obstructed larval recruitment (see Fig. 3).

An abundance increase inside the cage may result in emigration of mobile species out of the cage. Conversely, predators capable of passing the cage might migrate into the cage if abundance of their prey is higher there. The cage can also function as a refuge from predation by secondary carnivores for predatory species capable of passing the cage (Arntz, 1977). Thus, migration might camouflage or bias predation effects on community structure in the cage in several ways.

Species with the ability to recruit over the whole experimental period might have the same density in the cage and control, not because predation on these animals did not take place, but because there are always individuals ready to replace an individual removed by predation. In the inner Oslofjord Schram (1968) found that Polydora larvae were present all the year round.

Predators do not always remove the whole prey, for example only the siphon of bivalves or palps of polychaetes may be utilised. This form of predation results in a reduction in biomass but not in a reduction in abundance and would not have been recognised in my experiments.

The experimental box was situated on the natural sediment. This created a vertical barrier from the surface of the surrounding sediment to the surface of the sediment in the box. I postulate that this barrier is unimportant in restricting demersal fish from the control (gobids have been seen on the control). On the contrary, the experimental box may attract fish because the box represents heterogeneity on the natural sediment. Epibenthic predators relying on contact with the sediment for locomotion are more liable to be restricted by the barrier; however, even pagurids have been found in the control. I therefore conclude that most epibenthic predators are capable of advancing onto the experimental box, though abundance may be somewhat different from on the natural sediment.

\section{Interpretation of the results}

In the experiments from the inner Oslofjord, recruitment to the sediment in the cage is reduced by the net covering and by the fouling organisms on this net. Therefore the effect of predation cannot be estimated on the basis of abundance (reduced recruitment 
and reduced predation pressure have opposing effects on abundance). My results indicate that the effect of reduced recruitment on abundance is greater than the possible predation effect. When the taxa in the cage and the control are arranged according to relative abundance, a high correlation between rank in cage and rank in control (see Fig. $5 \mathrm{a}, \mathrm{b})$ is revealed.

Both predation and competitive interactions may alter relative abundance patterns. In the experiments of Reise (1978) there was no correlation between rank in control and cage (Fig 5d). In addition, several species were found exclusively in the control. Reise interpreted the difference between cage and control as a function of predation. Based on the argument that predation alters relative abundance and on the present results, I conclude that predation by epibenthic macrofauna does not seem to be of fundamental importance in structuring relative abundance between the recognised groups in an area with a moderately organically enriched sediment as found in the subtidal station in the inner Oslofjord. Further experiments with cages on natural sediment are, however, in progress in our laboratory to clarify this further.

Out of the 11 groups listed in Table 2 from the experiments at Farsund, 5 are not significantly different in abundance in the cage as compared with the control. The 6 remaining groups have either a significantly higher abundance in the cage (Tellinacea, Syllidae, indet. and Pholoë minuta) or a significantly higher abundance in the control (Prionospio malmgreni, Paraonidea, indet. and Microphthalmus abberans). These results are in contrast to the results from the inner Oslofjord experiments, where all groups had a lower abundance in the cage than in the control. I interpret this difference as an indication that there is no dramatic reduction in recruitment to the cage compared with the control in the experiments at Farsund. The results showing a significantly higher abundance in the cage for 3 groups are interpreted as an effect of reduced predation and that predation is an important factor in controlling abundance of small-sized tellinaceans, syllids and Pholoë minuta. However, other interpretations are possible.

Other authors recognize the significance of predation in the control of bivalve abundance. Segerstråle (1978) concludes that predation is an important factor in controlling abundance of Macoma baltica in the Baltic, and Reise (1977) demonstrates in some manipulative cage experiments in the intertidal that density of Macoma baltica spat is higher inside the cage than outside. Muus (1973) regards predation as a dominant cause of mortality among young bivalves. Virnstein (1979) states that the animals most affected by predation are those living close to the sediment surface, not living in tough tubes and not able to retract quickly to deeper parts of the sediment. Clearly, small-sized tellinaceans fall within this group.

The results demonstrate 3 groups which were significantly more abundant in the control than in the cage. These results are difficult to explain. However, some of the factors stated at the beginning of this section (for example competitive interactions with groups affected by reduced predation pressure) are possible explanations for the higher abundance in the control. My conclusion is that exclusion of epibenthic macropredators from subtidal sediments does not lead to a significant increase in abundance except for small-sized bivalves, Syllides and for Pholoë minuta от major changes in species composition in the area investigated.

My results on predation effects from unvegetated subtidal sediments, together with results from unvegetated intertidal mudflats, indicate that predation is of more limited 
importance in the subtidal than has previously been found for the intertidal (Naqvi, 1968; Reise, 1977a, b, 1978). To my knowledge, the only author concluding that predation is of limited importance in structuring communities on intertidal mudflats is Commito (1976).

If further investigations in the subtidal verify that predation is of limited importance in controlling community structure, this would be of significance in monitoring pollution effects on community structure. The fluctuations in community parameters due to predation would be less and therefore, the background noise in the measurement of pollution effects would be reduced.

Acknowledgements. This investigation is part of F. O. H. Project no. 203 under the Norwegian Marine Pollution Research and monitoring Program. I wish especially to thank Prof. John S. Gray for introducing me to the subject and for his support during this study. I am indebted to several people for laboratory work, diving assistance and for species identification. Foremost of these are Vernonica Alvarez Valderhaug, Hartvig Christie and Thomas Schram. I wish also to thank the abovementioned persons and in addition Ivar H. Hesthagen and Jens Koefoed for stimulating discussions during the study.

\section{LITERATURE CITED}

Arntz, W. E., 1977. Results and problems of an "unsuccessful" benthos cage predation experiment (Western Baltic) In: Biology of benthic organisms. Ed. by B. F. Keegan, P. O. Ceidigh \& P. J. S. Boaden. Pergamon Press, Oxford, 31-44.

Blegvad, H., 1927. Om fiskenes konsum av bunndyr. Et forsøg med oppvekst af bunndyr i kasser. Naturen 51, 22-29.

Commito, J. H., 1976. Predation, competition, life-history strategies, and the regulation of estuarine softbottom community structure. Ph. D. Thesis, Duke Univ., Durham, 201 pp.

Connell, J. H., 1961a. Effects of competition, predation by Thais lapillus, and other factors on natural populations of the barnacle Balanus balanoides. - Ecol. Monogr. 31, 61-104.

Connell, J. H., 1961b. The influence of interspecific competition and other factors on the distribution of the barnacle Chathamalus stellatus. - Ecology 42, 701-723.

Connell, J. H., 1972. Community interactions on marine rocky intertidal shores. - A. Rev. Ecol. Syst. 3, 169-192.

Menge, B. A. \& Sutherland, J. P., 1976. Species diversity gradients: Synthesis of the role of predation, competition and temporal heterogeneity. - Am. Nat. 110, 351-369.

Muus, K., 1973. Settling, growth and mortality of young bivalves in the Øresund. - Ophelia 12, 79-116.

Naqvi, S. M. Z., 1968. Effects of predation on infauna invertebrates of Alligator Harbor, Florida. Gulf Res. Rep. 2, 313-321.

Peterson, C. H., 1979a. The importance of predation and competition in organizing the intertidal epifauna communities of Barnegat Inlet, New Jersey. - Oecologia 39, 1-24.

Peterson, C. H., 1979b. Predation, competitive exclusion, and diversity in the soft-sediment benthic communities of estuaries and lagoons. In: Ecological processes in coastal and marine systems. Ed. by R. J. Levingstone. Plenum Press, New York. (In press.)

Reise, K., 1977a. Predator exclusion experiments in an intertidal mud flat. - Helgoländer wiss. Meeresunters. 30, 263-271.

Reise, K., 1977b. Predation pressure and community structure of an intertidal soft-bottom fauna. In: Biology of benthic organisms. Ed. by B. F. Keegan, P. O. Ceidigh \& P. J. S. Boaden. Pergamon Press, Oxford, 513-519.

Reise, K., 1978. Experiments on epibenthic predation in the Wadden Sea. - Helgoländer wiss. Meeresunters. 31, 55-101.

Schram, T. A., 1968. Studies on the meroplankton in the inner Oslofjord I. Composition of the plankton at Nakkholmen during a whole year. - Ophelia 5, 221-243. 
Segerstråle, S. G., 1978. The negative correlation between the abundances of the amphipod Pontoporeia and the bivalve Macoma in Baltic waters, and the factors involved. - Ann. zool. Fenn. 15, 143-145.

Virnstein, R. W., 1977. The importance of predation by crabs and fish on benthic infauna in Chesapeake bay. - Ecology 58, 1199-1217.

Virnstein, R. W., 1979. Predation on estuarine infauna: Response patterns of component species. Estuaries 2, 69-86.

Young, D. K. \& Young, M. W., 1978. Regulation of species densities of seagrass-associated macrobenthos: Evidence from field experiments in the Indian River estuary, Florida. - J. mar. Res. 36, 569-593. 